\title{
The catecholamine neurotransmitter precursor tyrosine increases anger during exposure to severe psychological stress
}

\author{
Harris R. Lieberman - Lauren A. Thompson - Christina M. Caruso • \\ Philip J. Niro • Caroline R. Mahoney • James P. McClung • Gregory R. Caron
}

Received: 20 September 2013 / Accepted: 22 August 2014 /Published online: 16 September 2014

(C) The Author(s) 2014. This article is published with open access at Springerlink.com

\begin{abstract}
Rationale Acute stress produces behavioral and physiological changes modulated by central catecholamines (CA). Stress increases CA activity, and depletion of CA stores reduces responses to stress. Increasing $\mathrm{CA}$ activity by administration of the dietary amino acid CA precursor tyrosine may increase responsiveness to stress. This study determined whether tyrosine enhances the ability of humans to respond to severe stress.

Methods Severe psychological stress was generated during training at Survival, Evasion, Resistance, and Escape (SERE) School. The acute stressor consisted of two mock interrogations conducted during several days of simulated captivity. Seventy-eight healthy male and female military personnel participated in this double-blind, between-subjects study, in which they received either tyrosine $(300 \mathrm{mg} / \mathrm{kg}, N=$ $36)$ or placebo $(N=36)$. Tyrosine (or placebo) was administered in food bars in two doses of $150 \mathrm{mg} / \mathrm{kg}$ each approximately 60 min before each mock interrogation. Mood (Profile of Mood States), saliva cortisol, and heart rate (HR) were assessed prior to stress exposure during a week of academic training preceding mock captivity and immediately following the mock interrogations.
\end{abstract}

H. R. Lieberman $(\bowtie) \cdot$ L. A. Thompson • C. M. Caruso • P. J. Niro • J. P. McClung

Military Nutrition Division, US Army Research Institute of Environmental Medicine, Kansas Street, Natick, MA 01760, USA e-mail: harris.lieberman@us.army.mil

C. R. Mahoney

Cognitive Sciences, US Army Natick Soldier Research, Development, and Engineering Center, Kansas Street, Natick, MA 01760, USA

G. R. Caron

SERE EAST, Center for Security Forces, Brunswick, ME 04011, USA
Results The severe stress produced robust effects on mood (i.e., increased tension, depression, anger, fatigue, vigor, and confusion; $p<.001)$, cortisol, and HR $(p<.001)$. Tyrosine increased anger $(p=.002$, ANOVA treatment condition by test session interaction) during stress but had no other effects.

Conclusion Tyrosine did not alter most subjective or physiological responses to severe acute stress, but it increased ratings of anger. The modest increase in anger may be an adaptive emotional response in stressful environments.

Keywords Mood · Cortisol · Amino acid · Norepinephrine · Dopamine $\cdot$ SERE $\cdot$ Interrogation $\cdot$ Military

\section{Introduction}

Acute stress produces a range of behavioral effects in both laboratory animals and humans. In laboratory animals, acute intense physiological stressors such as cold, heat, high altitude, or psychological stressors such as restraint (Stone 1975; Gray 1982; Shurtleff et al. 1993) cause animals to become less responsive to the environment, explore less, and appear generally debilitated (Stone 1975; Gray 1982; Shurtleff et al. 1993). In humans, acute stress produces similar behavioral symptoms (Gray 1982).

Acute stress increases release and turnover of the catecholamine neurotransmitters norepinephrine (NE) and dopamine (DA) in critical areas of the brain such as the hippocampus and prefrontal cortex (Stone 1975; Anisman and Sklar 1979; Nisenbaum and Abercrombie 1993; Sudha and Pradhan 1995; Cabib and Puglisi-Allegra 1996; Goldwater et al. 2009). Release of NE as well as DA may, under certain conditions, be modulated by availability of its dietary precursor tyrosine (Wurtman and Fernstrom 1975; During et al. 1989; Lieberman 1994; Yeghiayan et al. 2001; Lieberman 
et al. 2005b; Fernstrom and Fernstrom 2007). Notably, stressful environments may result in a depletion of the NE precursor, tyrosine, limiting optimal synthesis of NE. This depletion can be reduced by ingestion of tyrosine, a large neutral amino acid (LNAA) found in animal and plant protein foods (Lehnert et al. 1984a; Lehnert et al. 1984b; Brady et al. 1988). Tyrosine administration can increase NE release in the brain when NE neurons are highly active, such as during acute stress (Yeghiayan et al. 2001). Thus, supplemental tyrosine can increase brain synthesis and release of catecholamines, especially norepinephrine and also perhaps dopamine, and may in this way reduce the behavioral and physiological consequences of stress (Lehnert et al. 1984a; Lehnert et al. 1984b; Banderet and Lieberman 1989; Shurtleff et al. 1993; Lieberman 1994; Deijen and Orlebeke 1994; Neri et al. 1995; Thomas et al. 1999; Magill et al. 2003; Deijen 2005; Mahoney et al. 2007). In laboratory animals, tyrosine reduces responses to stressors such as heat, tail shock, and hypobaric hypoxia (Lehnert et al. 1984a; Lehnert et al. 1984b; Lieberman 1994; Shukitt-Hale et al. 1996; Lieberman et al. 2005b).

Although standardized laboratory methods exist for inducing acute stress in human volunteers, these procedures have relatively modest effects and perhaps are not strong enough to permit detection of the effects of tyrosine in humans (Owasoyo et al. 1992). Survival, Evasion, Resistance, and Escape (SERE) School is a type of controlled military training that is highly stressful. SERE training induces biochemical, cardiovascular, and behavioral changes characteristic of acute, severe stress exposure (Morgan et al. 2000a; Morgan et al. 2002; Morgan et al. 2004; Steffian et al. 2005; Taylor et al. 2007), higher than levels typically observed in other highly stressful situations, such as skydiving (Morgan et al. 2000a; Morgan et al. 2002; Taylor et al. 2007). Therefore, using a double-blind, placebo-controlled design, we examined the effects of consuming the amino acid tyrosine, in the form of a food bar, on mood, cortisol, and heart rate in the controlled, highly stressful environment of SERE School. We hypothesized that tyrosine would reduce the behavioral and physiological consequences of acute, severe psychological stress, relative to placebo.

\section{Methods}

A double-blind, placebo-controlled, between-subjects design was employed. This study was conducted at the US Navy SERE School in Brunswick, ME. The protocol and all procedures were approved by the National Naval Medical Center and US Army Research Institute of Environmental Medicine Institutional Review Boards and conducted in accordance with the Declaration of Helsinki. Written informed consent was obtained from all volunteers.

Subjects

Seventy-eight healthy volunteers (72 males and 6 females; mean age $25 \pm 4$ years; mean body weight $80.9 \pm 11.4 \mathrm{~kg}$ ) completed the study (Table 1). Prior to admission to SERE School, all students received a medical clearance documenting their good health. All volunteers were either active duty US Navy $(N=59)$ or Marine $(N=19)$ personnel enrolled in the US Navy SERE School, Brunswick, ME. They had an average 4 years of active duty military service. Use of psychotropic medications or illegal substances is not permitted at SERE School, and random urine tests are periodically conducted on all military personnel.

\section{SERE School}

Training in SERE School is required for US military personnel at high risk of capture. At the SERE School at which this study was conducted, each course lasted two weeks, and consisted of three sequential phases: (1) a week of academic classroom training, (2) several days of survival training conducted in a natural environment, and (3) the final portion of the course which was a captivity phase lasting several days. During the classroom portion, students were trained in survival, evasion, resistance, and escape techniques. During the second phase, they completed a survival field exercise. In the third phase, trainees were "captured" and applied their newly learned resistance skills in a stressful captivity environment that simulated actual captivity, including mock interrogations which generated particularly intense levels of acute stress (Morgan et al. 2000a). One objective of realistic exposure to stress is to enhance the ability to resist future stress (Morgan et al. 2000a; Morgan et al. 2002; Taylor et al. 2007).

\section{Procedures}

Volunteers were recruited and completed a demographic questionnaire during day 1 of the course (during the academic/ classroom phase of SERE School). During this phase, they practiced a standardized mood questionnaire, the Profile of Mood States (POMS), on three occasions for $5 \mathrm{~min}$ each, twice on day 2 and once on day 3. The final POMS practice session conducted on day 3 served as a pre-stress baseline condition (session 1). A baseline measure of heart rate was obtained on day 2 of the course. In addition, three baseline saliva samples were obtained on day 2 of the course in the morning (baseline sample "A-morning"), midday (baseline 
Table 1 Volunteer demographics by treatment group

\begin{tabular}{|c|c|c|c|}
\hline & Placebo & Tyrosine & $\begin{array}{l}\text { Level of significance, } \\
p \text { value }\end{array}$ \\
\hline Age (years, $M \pm \mathrm{SD}$ ) & $24.87 \pm 3.36$ & $24.85 \pm 4.32$ & $.980^{\mathrm{a}}$ \\
\hline Height (cm, $M \pm \mathrm{SD}$ ) & $177.72 \pm 8.53$ & $177.17 \pm 7.59$ & $.754^{\mathrm{a}}$ \\
\hline Weight (kg, $M \pm \mathrm{SD})$ & $81.57 \pm 12.73$ & $80.05 \pm 10.16$ & $.557^{\mathrm{a}}$ \\
\hline Active duty (years, $M \pm \mathrm{SD}$ ) & $3.97 \pm 3.23$ & $3.90 \pm 3.04$ & $.918^{\mathrm{a}}$ \\
\hline Sex (males/females, $N$ ) & $37 / 2$ & $35 / 4$ & $.237^{\mathrm{b}}$ \\
\hline
\end{tabular}

${ }^{\mathrm{a}} t$ test

${ }^{\mathrm{b}}$ Fisher's exact test of independence

sample "B-midday"), and evening (baseline sample "Cevening").

Subsequently, during the final phase of SERE School (the captivity phase), mood was assessed and saliva collected on three separate occasions. The first two of these test sessions (sessions 2 and 3) were conducted immediately following interrogation sessions and were separated by $5-6 \mathrm{~h}$. Tyrosine or placebo was administered $1-2 \mathrm{~h}$ prior to both sessions 2 and 3 as described below. A fourth session (session 4) was conducted when the captivity phase was nearing completion, approximately $12 \mathrm{~h}$ after session 3 . Additional scheduling details cannot be specified here because providing them would diminish the effectiveness of SERE training.

\section{Tyrosine administration}

Volunteers were randomly assigned in a counterbalanced order to either tyrosine or placebo; 36 received tyrosine and 36 received placebo. Tyrosine or placebo was administered in food bars prior to both sessions 2 and 3. The bars were manufactured by the Natick Soldier Research, Development and Engineering Center (NSRDEC) and were composed of a matrix of approximately $7 \%$ fat, $2 \%$ protein (other than tyrosine), and $70 \%$ carbohydrate. The total dose of tyrosine administered was $300 \mathrm{mg} / \mathrm{kg} ; 150 \mathrm{mg} / \mathrm{kg}$ was administered in one bar given $1 \mathrm{~h}$ prior to the first interrogation (session 2) and a second bar was consumed $1-2 \mathrm{~h}$ prior to the second interrogation (session 3). The size of the food bars each volunteer received varied depending on his/her body weight. Every gram of tyrosine was administered with $5 \mathrm{~g}$ of the food bar matrix. For example, a 70-kg volunteer received a total of $21 \mathrm{~g}$ of tyrosine and $105 \mathrm{~g}$ of the matrix, combined for a total of $126 \mathrm{~g}$. A placebo-treated volunteer of the same weight would have received $126 \mathrm{~g}$ of the matrix alone. This pattern and level $(300 \mathrm{mg} / \mathrm{kg}$ ) of dosing is similar to that used in previous tyrosine studies and substantially increases plasma tyrosine levels (Glaeser et al. 1979; Banderet et al. 1996). In one of these studies, a dose of $150 \mathrm{mg} / \mathrm{kg}$ of tyrosine increased plasma tyrosine threefold $2 \mathrm{~h}$ after administration and had a minimal effect on the other large neutral amino acids (LNAAs) (Glaeser et al. 1979). Banderet et al. (1996) observed even larger increases in plasma tyrosine levels when they administered tyrosine in a food bar similar to the bar used in this study. There was no discernible difference in the taste of the two treatment bars. No other food or dietary supplements were provided prior to the administration of treatment bars; water was available to SERE students throughout training.

\section{POMS questionnaire}

The POMS is a widely used, standardized, computer- or paper-and-pencil-administered inventory of mood states (McNair et al. 1971). It provides a comprehensive assessment of a wide range of mood states and captures the fundamental domains of human affect (McNair et al. 1971). It is sensitive to a wide variety of nutritional manipulations, including tyrosine, environmental factors, sleep loss and subclinical doses of various drugs, and a variety of stressors including sleep deprivation and environmental extremes (Banderet and Lieberman 1989; Shukitt-Hale et al. 1998; Lieberman et al. 2002a; Lieberman et al. 2002b; Lieberman et al. 2002c; Scott et al. 2006; Lieberman et al. 2009; Fogt et al. 2010). It takes less than $5 \mathrm{~min}$ to complete. Volunteers rated a series of 65 mood-related adjectives with regard to how they were feeling "right now" on a scale of 0 (not at all) to 4 (extremely). When analyzed, the adjectives provide six independent, factoranalytically derived mood subscales (tension, depression, anger, vigor, fatigue, and confusion) (McNair et al. 1971).

\section{Cortisol}

To assess the physiological level of stress induced by captivity, salivary cortisol was measured during academic and captivity phases of SERE School. Saliva cortisol is frequently used to assess the impact of psychological and physical stress on humans (Kahn et al. 1988; Opstad 1994; Morgan et al. 
2000a; Lieberman et al. 2005a). Cortisol levels in saliva are highly correlated with those in blood (Kahn et al. 1988; Kirschbaum and Hellhammer 1989). Increased release of the hormone cortisol is the most widely accepted biological marker of activation of the hypothalamus-pituitary-adrenal axis (HPA) in humans (Laudat et al. 1988; Kirschbaum and Hellhammer 1989).

Cortisol is released in a circadian pattern, with the highest level in the morning. Therefore, during baseline testing, it was assessed three times over the course of a single day, session 1:A-morning $(0600 \mathrm{~h})$, session 1:B-midday $(1200 \mathrm{~h})$, and session 1:C-evening $(1630 \mathrm{~h})$, during the academic, lowerstress phase of SERE School. This permitted a comparison of cortisol release during the captivity phase to the equivalent time of day of baseline testing conducted during academic week. During the captivity phase of the study, saliva samples were collected each time mood was assessed (sessions 2, 3, and 4).

Ten milliliters of saliva was collected in cryovials during each session. Five minutes before saliva collection, volunteers rinsed their mouths with water, placed a short straw in their mouth, and allowed saliva to flow (unstimulated) into a cryovial. The samples were stored at $-70{ }^{\circ} \mathrm{C}$ and shipped on dry ice to the Pennington Biomedical Research Center (Baton Rouge, LA) where they were assayed for cortisol using standard procedures.

\section{Heart rate}

Heart rate (HR) was assessed using the Hidalgo Equivital ${ }^{\mathrm{TM}}$ Vital Sign Detection System (VSDS) (Hidalgo Ltd., Swavesey, Cambridge, UK), a chest-worn monitor designed to function in harsh environments. Baseline data were collected for at least $4 \mathrm{~h}$ on day 2 of the academic instructional phase of SERE School. Mean HR for this period was computed. During the captivity phase, the VSDS was placed on the volunteer's chest before they received their first treatment bar and was removed after the second interrogation session (session 3) was completed. Peak HRs were determined for the periods during the two interrogations.

\section{Statistical analysis}

Statistical analysis was conducted using the IBM SPSS statistical package version 19.0 (IBM SPSS, Chicago, IL). Descriptive data are presented as mean \pm SEM. A two-tailed $p$ value of $\leq 0.05$ was considered statistically significant. Chi-square or Fisher's exact test of independence were conducted to determine if treatment groups varied in demographic composition. Repeated measures ANOVA were used to determine if significant differences in mood, HR, and cortisol were present across the test sessions. A within-subjects factor of test session measured effects of SERE School over time on mood, and a between-subjects factor tested for tyrosine vs. placebo effects. Significant main or interaction effects were analyzed using the Least Significant Difference (LSD) post-hoc test.

Because cortisol is released in a manner that is dependent on time of day, separate ANOVAs for this parameter were conducted by matching and comparing equivalent times of saliva collection during academic week and captivity week. Since the initial interrogation was conducted midday for subjects in the study, the session 1:B-midday $(1200 \mathrm{~h})$ baseline saliva session was used for comparison to it; for the second interrogation, conducted in the evening, the appropriate comparison was the session 1:C-evening baseline saliva sample $(1630 \mathrm{~h})$. The final captivity week session (session 4) was conducted in the morning, so the session 1:A-morning baseline session, conducted at $0600 \mathrm{~h}$, was used for comparison.

\section{Results}

As illustrated in Table 1, there were no statistically significant differences in assignment of students to treatment condition.

\section{Mood}

Exposure to the captivity phase of SERE School significantly altered every subscale of the POMS (tension, depression, anger, fatigue, vigor, confusion, and total mood disturbance) as indicated by significant within-subject time effects on ANOVA $(p<.001$, all subscales and total mood disturbance; Fig. 1). Post-hoc testing demonstrated that baseline scores (session 1) were always significantly different from captivity week sessions, with the greatest differences at sessions 2 and 3 , the sessions immediately following mock interrogations (Fig. 1). The magnitude of the changes in all mood states were generally greatest when comparing session 1 to session 3; tension increased $392 \%$, depression increased $317 \%$, anger increased $171 \%$, fatigue increased $183 \%$, vigor decreased $44 \%$, confusion increased $368 \%$ (Fig. 1), and the total mood disturbance score (not shown) increased $601 \%$.

Tyrosine administration affected the mood state of anger as indicated by significant treatment effects between-subjects $(p=.02)$ and interaction $(p=.002)$ effects on ANOVA (Fig. 1). Post-hoc testing demonstrated that anger levels were greater following interrogation at session $3(p=.03)$ and session 4 $(p<.001)$ in those receiving the tyrosine-containing food bar. No other mood parameter was significantly affected by tyrosine administration (tension: between subjects $[p=.11]$, interaction $[p=.33]$; depression: between subjects $[p=.24]$, interaction $[p=.48]$; vigor: between subjects $[p=.70]$, interaction $[p=.06]$; fatigue: between subjects [ $p=.20]$, interaction $[p=.35]$; confusion: between subjects $[p=.63]$, interaction $[p=.64]$ ). 
Fig. 1 Changes in the six subscales of the POMS over the course of SERE training as a function of tyrosine vs. placebo administration. Tyrosine significantly increased the anger subscale at sessions 3 and 4 during the stressful captivity phase of SERE School. Session 1 was conducted prior to treatment administration during academic week, the low-stress portion of SERE School. Tyrosine or placebo was administered just prior to sessions 2 and 3 as shown by the arrows. Session 4 was conducted the following day. Significant effects of tyrosine compared to placebo on post-hoc testing at specific time points are indicated by a \# $(p<.03)$ or \#\# $(p<.001)$. Significant changes on post-hoc testing when session 2 , 3 , or 4 was compared to session 1 (academic week-baseline) are indicated by $*(p<.001)$
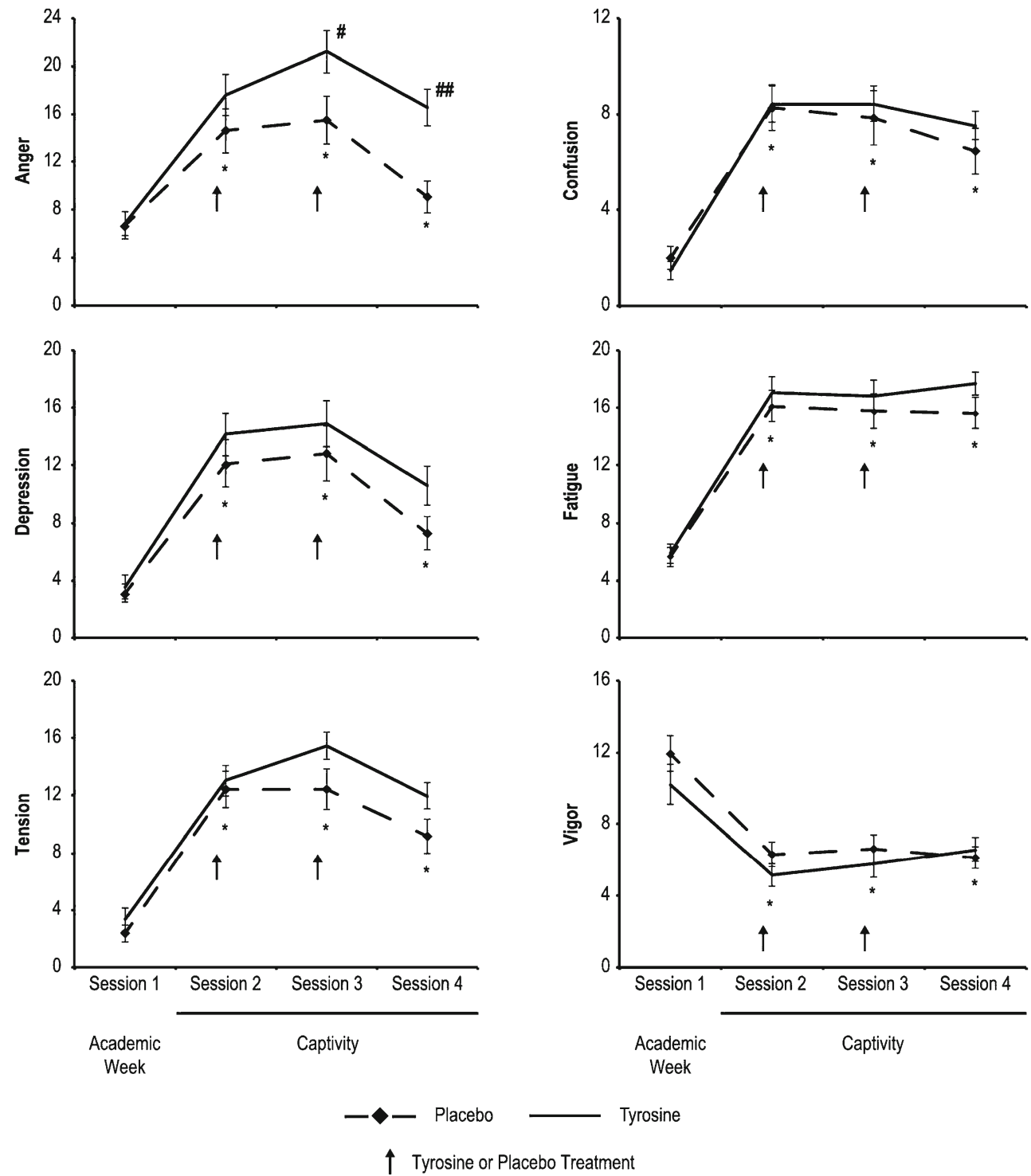

\section{Cortisol}

Saliva cortisol levels were elevated after the two interrogation sessions compared to the appropriate time-matched baseline measures $(p<.001$, Fig. 2$)$. The final captivity week session (session 4) was not significantly different from the appropriate baseline control measure (Fig. 2). There were no significant differences on ANOVA when cortisol levels of volunteers receiving tyrosine-containing food bars were compared to those of volunteers receiving placebo food bars.

\section{Heart rate}

Mean baseline HR was $80.1 \pm 1.6$ beats/min. Mean peak HR during the first interrogation session was $166.7 \pm 2.4$ beats $/ \mathrm{min}$ and during the second interrogation session, $173.5 \pm 1.9$ beats/ min (Fig. 3). There was a significant effect of test session on
HR $(p<.001)$. Post-hoc testing demonstrated that HR was lower during baseline testing $(p<.001)$ compared to either interrogation session, and during interrogation session $2, \mathrm{HR}$ was higher than interrogation session $1(p<.008$, Fig. 3$)$. There were no significant differences in HR between tyrosine- and placebo-treated volunteers on ANOVA.

\section{Discussion}

This study demonstrates that during severe psychological stress, double-blind administration of the dietary catecholamine neurotransmitter precursor tyrosine in a food bar increases the mood of anger as measured by a validated, selfreport mood questionnaire. Tyrosine's effects on anger were robust and consistent across multiple test sessions. At the 


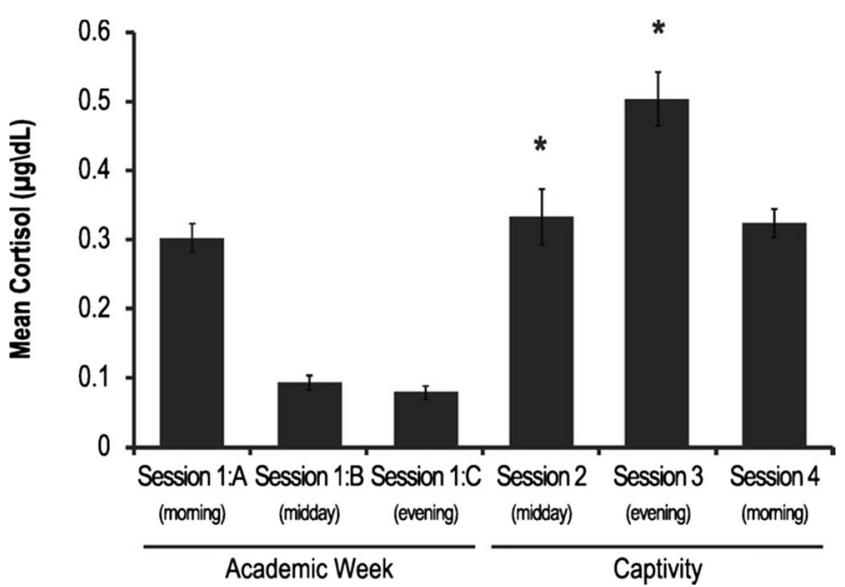

Fig. 2 Cortisol levels $(\mu \mathrm{g} / \mathrm{dL})$ during academic week (session 1: Amorning, B-midday, and C-evening) and captivity (sessions 2, 3, 4). All session 1 samples (A, B, C) were obtained during baseline testing (prestress exposure). Sessions 2, 3, and 4 were conducted sequentially over the course of the captivity phase of SERE School. Session 2 was conducted midday immediately following the first interrogation. Session 3 was conducted immediately following the second interrogation. Session 4 was conducted in the morning when the captivity phase of SERE training was nearing completion. Due to substantial circadian variations in release of cortisol, statistical comparisons of captivity testing sessions were only conducted by comparing each session to the assessment session conducted at the equivalent time of day during academic week $\left({ }^{*} p<.001\right.$ on the within-subject factor of ANOVA)

baseline test session, the tyrosine and placebo groups displayed equivalent and low levels of anger. Immediately after mock interrogations, considered the most stressful experiences at SERE School (Morgan et al. 2000a), the mood of anger substantially increased in both groups, but the increase was significantly greater in the tyrosine-treated group. The mood of anger may, under certain circumstances, including SERE School, be a justified and appropriate response to provocation and has been found to be associated with the stress of SERE School (Taylor et al. 2009). It is reported that short-term anger provides a sense of control and optimism in healthy adults who are exposed to a stressful situation (Lerner et al. 2007). Anger may enhance SERE students' ability to

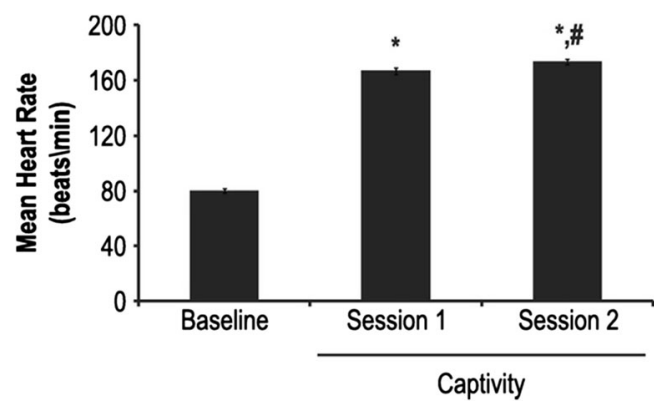

Fig. 3 Mean HR (beats/min) during baseline testing conducted during the academic non-stressful portion of SERE School and peak heart rates during sessions 2 and 3 when interrogations were being conducted. On post-hoc testing, mean peak session 2 and session 3 HRs were significantly higher than baseline $\left({ }^{*} p<.001\right)$. Session 3 HR was significantly higher than Session 2 HR $(\# p=.008)$ effectively respond to the stress of mock captivity, including mock interrogations, consistent with other positive effects of appropriately focused anger (Lerner and Keltner 2001). However, an increase in anger may not be adaptive and, in certain circumstances, may be counterproductive.

Future studies should investigate whether increased anger is beneficial in SERE School and other circumstances or has negative consequences, and whether other mood states are altered by tyrosine administration. Information on other outcomes related to coping with stress, such as ability to learn coping strategies taught at SERE School and speed of recovery, would also help establish whether tyrosine is beneficial. We are not aware of any evidence that tyrosine or any other food component or drug directly affects the mood state of anger, but tyrosine has never been tested in an environment that induces high levels of anger as well as intense levels of psychological stress.

\section{Comparison to other stress paradigms}

Concomitant assessment of the stress hormone cortisol, heart rate, and self-reported tension-anxiety (POMS) confirmed that very high levels of stress were induced by the SERE environment, especially during mock interrogations, and illustrate SERE School's uniqueness and robustness. The changes in these parameters we observed exceeded changes typically observed in other acutely stressful situations such as skydiving, when patients undergo major surgery, when physicians perform difficult surgical procedures, or in laboratory simulations of psychological stress (Kirschbaum et al. 1993; Arora et al. 2010a; Arora et al. 2010b). For example, peak HR during the second mock interrogation reached a mean peak level of $173.5 \pm 1.9$ beats $/ \mathrm{min}$. This is an extraordinarily high level for individuals not engaged in an intense aerobic activity. We are not aware of any studies of psychological stress where peak HR levels of this magnitude have been observed. Furthermore, in our study, cortisol was elevated by a factor of 5 during the second interrogation (session 3 ) relative to the comparable academic week session (the session 1:C-evening measurement). In a study using the Trier Social Stress Test, a widely used stress paradigm, saliva cortisol was elevated by a factor of 2 or 3 (Kirschbaum et al. 1993).

The nature and magnitude of the level of stress we observed are consistent with previous studies of SERE School which observe very high levels of cortisol and changes in other stress hormones and cardiovascular function (Morgan et al. 2000a; Morgan et al. 2000b; Morgan et al. 2001; Morgan et al. 2002; Morgan et al. 2004; Taylor et al. 2007). The high level of stress induced by the captivity phase of SERE School indicates that it is comparable to the stress of actual combat (Morgan et al. 2000a; Morgan et al. 2000b; Morgan et al. 2001; Morgan et al. 2002; Morgan et al. 2004; Taylor et al. 2007). Future research should utilize the unique opportunity 
provided by SERE training to examine various interventions that could prevent the long-term adverse consequences of exposure to severe stress such as post-traumatic stress disorder (PTSD) and depression. In addition, the large number of military personnel undergoing such training provides an opportunity for studying how individual differences, such as personality and genetic variation, influence the stress response.

Central catecholaminergic systems, learned helplessness and anger

Central noradrenergic systems are critical in the response to acute stress (Stone 1975; Nisenbaum and Abercrombie 1993; Sudha and Pradhan 1995; Dronjak et al. 2004; Morilak et al. 2005; Goldwater et al. 2009) and sensitive to treatment with exogenous tyrosine (Lehnert et al. 1984a; Brady et al. 1988; Lieberman 1994). Dopamine also increases during acute stress and may be precursor loading-sensitive, but the evidence is limited and inconsistent (Stone 1975; During et al. 1989; Westerink and De Vries 1991). During acute stress, tyrosine administration increases central noradrenergic activity and the ability of humans and other animals to appropriately respond to various stressors (Lieberman 1994). Inability to appropriately respond to acute, uncontrollable stress has been termed learned helplessness and is associated with reduced central noradrenergic activity (Gray and McNaughton 1996). Learned helplessness is one potential outcome of captivity (Steffian et al. 2005). In a standard model of depression, the forced swim test, animals treated with tyrosine, compared to placebo, swim for longer periods of time, an indication of enhanced resistance to acute stress (Rauch and Lieberman 1990; Yeghiayan et al. 2001). For humans in the SERE environment, tyrosine may have parallel effects, potentially increasing the ability to resist by increasing anger. Anger may be an appropriate response to the stress of the forced captivity and interrogation at SERE School, and we hypothesize that tyrosine, dietary precursor of NE, increases the magnitude of this response by increasing central NE levels, but note that changes in DA or both DA and NE may be responsible for the changes we observed.

The regulation of anger is a high-level cortical process, and the primary source of noradrenergic input to cerebral cortex is the locus coeruleus (LC) (Aston-Jones and Cohen 2005). The LC-NE system, which has widely distributed projections to the cortex, is associated with a range of critical behavioral functions including arousal, emotion, attention to task-focused behaviors, and motivation (Aston-Jones and Cohen 2005). Therefore, the changes in anger we observed due to tyrosine administration suggest that anger is regulated in part by NA neurons of the LC. This hypothesis is consistent with literature indicating that the LC innervates the orbitofrontal cortex (OFC), the brain region most closely associated with the modulation of anger (Morecraft et al. 1992; Murphy et al. 2003; Pichon et al. 2008).

Study weaknesses

One weakness of this study, which is typically associated with realistic field studies, is uncontrolled variation in the testing environment and inability to include other dependent measures such as blood sampling or a measure of central or peripheral catecholamine levels. A measure of central catecholaminergic activity, such as collection of cerebrospinal fluid which contains central CA, would be particularly revealing (Watson and Wilk 1975).

\section{Conclusion}

In conclusion, this double-blind, placebo-controlled study demonstrates that the administration of the amino acid tyrosine in the form of a food bar increases the mood of anger, a potentially appropriate response to the severe psychological stress of SERE School. Tyrosine may be an effective intervention when individuals are exposed to acute, severe psychological stress, but additional research is required to replicate and extend these findings. In addition, this study confirms and extends previous research on the nature and magnitude of the psychological stress induced by SERE School. Changes in HR may be the best overall indicator of peak levels of stress during SERE School since it can be assessed with unobtrusive ambulatory monitors during actual interrogations. This study also provides new information on simultaneously acquired behavioral, physiological, and biochemical measures during acute severe psychological stress.

Acknowledgments The authors wish to acknowledge the volunteers that participated in the present study as well as the staff at the US Navy SERE School in Brunswick, ME, for allowing access to their students and facilities. The authors would also like to thank Jack Briggs and Paul Maguire for their assistance with the development and preparation of the food bars used in this study and Phil Karl, Tony Rogers, Mike Stanger, and Brooke Green for their assistance with data collection. The opinions or assertions contained herein are the private views of the authors and are not to be construed as official or as reflecting the views of the US Army or Department of Defense. Human subjects participated in these studies after giving their free and informed voluntary consent. The investigators have adhered to the policies for the protection of human subjects as prescribed in Army Regulation 70-25, and the research was conducted in adherence with the provisions of 32 CFR Part 219. Citations of commercial organizations and trade names in this report do not constitute an official US Department of the Army endorsement or approval of the products or services of these organizations. This study was supported by the US Army Medical Research and Materiel Command.

Conflict of interest None. 
Open Access This article is distributed under the terms of the Creative Commons Attribution License which permits any use, distribution, and reproduction in any medium, provided the original author(s) and the source are credited.

\section{References}

Anisman H, Sklar LS (1979) Catecholamine depletion in mice upon reexposure to stress: mediation of the escape deficits produced by inescapable shock. J Comp Physiol Psychol 93: 610-625

Arora S, Sevdalis N, Aggarwal R, Sirimanna P, Darzi A, Kneebone R (2010a) Stress impairs psychomotor performance in novice laparoscopic surgeons. Surg Endosc 24:2588-2593

Arora S, Tierney T, Sevdalis N, Aggarwal R, Nestel D, Woloshynowych M, Darzi A, Kneebone R (2010b) The Imperial Stress Assessment Tool (ISAT): a feasible, reliable and valid approach to measuring stress in the operating room. World J Surg 34:1756-1763

Aston-Jones G, Cohen JD (2005) An integrative theory of locus coeruleus-norepinephrine function: adaptive gain and optimal performance. Ann Rev Neurosci 28:403-450

Banderet LE, Lieberman HR (1989) Treatment with tyrosine, a neurotransmitter precursor, reduces environmental stress in humans. Brain Res Bull 22:759-762

Banderet LE, Young AJ, Lieberman HR, Castellani JW, Rice V (1996) Testing the efficacy of administering tyrosine for reducing environmental stress (cold) in women. U.S. Army Research Institute of Environmental Medicine, Technical Report D1950110. Available via DTIC http://www.dtic.mil/docs/citations/ADA364136. Accessed 14 January 2014

Brady K, Brown JW, Thurmond JB (1988) Behavioral and neurochemical effects of dietary tyrosine in young and aged mice following cold swim stress. Pharmacol Biochem Behav 12: 667-674

Cabib S, Puglisi-Allegra S (1996) Stress, depression and the mesolimbic dopamine system. Psychopharmacology (Berl) 128:331-342

Deijen JB (2005) Tyrosine. In: Lieberman HR, Kanarek R, Prasad C (eds) Nutritional neuroscience. CRC Press LLC, Boca Raton, FL, pp 363-381

Deijen JB, Orlebeke JF (1994) Effect of tyrosine on cognitive function and blood pressure under stress. Brain Res Bull 33:319-323

Dronjak S, Gavrilović L, Filipović D, Radojcić MB (2004) Immobilization and cold stress affect sympatho-adrenomedullary system and pituitary-adrenocortical axis of rats exposed to longterm isolation and crowding. Physiol Behav 81:209-215

During MJ, Acworth IN, Wurtman RJ (1989) Dopamine release in rat striatum: physiological coupling to tyrosine supply. J Neurochem 52:1449-1454

Fernstrom JF, Fernstrom MH (2007) Tyrosine, phenylalanine, and catecholamine synthesis and function in the brain. J Nutr 137:1539S$1547 \mathrm{~S}$

Fogt DL, Kalns JE, Michael DJ (2010) A comparison of cognitive performance decreases during acute, progressive fatigue arising from different concurrent stressors. Mil Med 175:939-944

Glaeser BS, Melamed E, Growdon JH, Wurtman RJ (1979) Elevation of plasma tyrosine after a single oral dose of L-tyrosine. Life Sci 25: 264-271

Goldwater DS, Pavlides C, Hunter RG, Bloss EB, Hof PR, McEwen BS, Morrison JH (2009) Structural and functional alterations to rat medial prefrontal cortex following chronic restraint stress and recovery. Neuroscience 164:798-808

Gray JA (1982) Neuropsychology of anxiety. Oxford University Press, Oxford
Gray JA, McNaughton N (1996) The neuropsychology of anxiety. Reprise. In: Hope DA (ed) Nebraska Symposium on Motivation, vol. 43, pp. 61-134

Kahn JP, Rubinow DR, Davis CL, Kling M, Post RM (1988) Salivary cortisol: a practical method for evaluation of adrenal function. Biol Psychiatry 23:335-349

Kirschbaum C, Hellhammer DH (1989) Salivary cortisol in psychobiological research: an overview. Neuropsychobiology 22:150-169

Kirschbaum C, Pirke KM, Hellhammer DH (1993) The 'Trier Social Stress Test' - a tool for investigating psychobiological stress responses in a laboratory setting. Neuropsychobiology 28:76-81

Laudat MH, Cerdas S, Fournier C, Guiban D, Guilhaume B, Luton JP (1988) Salivary cortisol measurement: a practical approach to assess pituitary-adrenal function. J Clin Endocrin Metab 66:343-348

Lehnert H, Reinstein DK, Strowbridge BW, Wurtman RJ (1984a) Neurochemical and behavioral consequences of acute uncontrollable stress: effects of dietary tyrosine. Brain Res 303:215-223

Lehnert H, Reinstein DK, Wurtman RJ (1984b) Tyrosine reverses the depletion of brain norepinephrine and the behavioral deficits caused by tail-shock stress in rats. In: Stress: the role of the catecholamines and other neurotransmitters. Gordon and Beach, New York, pp. 81-91

Lerner JS, Dahl RE, Hariri AR, Taylor SE (2007) Facial expressions of emotion reveal neuroendocrine and cardiovascular stress responses. Biol Psychiatry 61:253-260

Lerner JS, Keltner D (2001) Fear, anger and risk. J Pers Soc Psychol 81: 146-159

Lieberman HR (1994) Tyrosine and stress: human and animal studies. In: Food components to enhance performance. National Academy, Washington, DC, pp. 277-299

Lieberman HR, Bathalon GP, Falco CM, Georgelis JH, Morgan CA III, Niro P, Tharion WJ (2002a) The "fog of war": documenting cognitive decrements associated with the stress of combat. In: Proceedings of the 23rd army science conference. Orlando, FL

Lieberman HR, Bathalon GP, Falco CM, Kramer FM, Morgan CA III, Niro P (2005a) Severe decrements in cognition function and mood induced by sleep loss, heat, dehydration, and undernutrition during simulated combat. Biol Psychiatry 57:422-429

Lieberman HR, Castellani JW, Young AJ (2009) Cognitive function and mood during acute cold stress after extended military training and recovery. Aviat Space Environ Med 80:629-636

Lieberman HR, Falco CM, Slade SS (2002b) Carbohydrate administration during a day of sustained aerobic activity improves vigilance, assessed with a novel ambulatory monitoring device, and mood. Am J Clin Nutr 76:120-127

Lieberman HR, Georgelis JH, Maher TJ, Yeghiayan SK (2005b) Tyrosine prevents effects of hyperthermia on behavior and increases norepinephrine. Physiol Behav 84:33-38

Lieberman HR, Tharion WJ, Shukitt-Hale B, Speckman KL, Tulley R (2002c) Effects of caffeine, sleep loss and stress on cognitive performance and mood during U.S. Navy SEAL training. Psychopharmacology 164:250-261

Magill RA, Waters WF, Bray GA, Volaufova J, Smith SR, Lieberman HR, McNevin N, Ryan DH (2003) Effects of tyrosine, phentermine, caffeine, D-amphetamine and placebo on cognitive and motor performance deficits during sleep deprivation. Nutr Neurosci 6:237246

Mahoney CR, Castellani JW, Kramer FM, Young A, Lieberman HR (2007) Tyrosine supplementation mitigates working memory decrements during cold exposure. Physiol Behav 92:575-582

McNair DM, Lorr M, Droppleman LF (1971) Profile of mood states manual. Educational and Industrial Testing Service, San Diego, CA

Morecraft RJ, Geula C, Mesulam MM (1992) Cytoarchitecture and neural afferents of orbitofrontal cortex in the brain of the monkey. J Comp Neurol 323:341-358

Morgan CA III, Rasmusson AM, Wang S, Hoyt G, Hauger RL, Hazlett G (2002) Neuropeptide-Y, cortisol and subjective distress in humans 
exposed to acute stress: replication and extension of previous report. Biol Psychiatry 52:136-142

Morgan CA III, Wang S, Mason J, Southwick SM, Fox P, Hazlett G, Charney DS, Greenfield G (2000a) Hormone profiles in humans experiencing military survival training. Biol Psychiatry 47:891-901

Morgan CA III, Wang S, Rasmusson AM, Hazlett G, Anderson G, Charney DS (2001) Relationship among plasma cortisol, catecholamines, neuropeptide $Y$, and human performance during exposure to uncontrollable stress. Psychosom Med 63:412-422

Morgan CA III, Wang S, Southwick SM, Rasmusson A, Hazlett G, Hauger RL, Charney DS (2000b) Plasma neuropeptide-Y concentrations in humans exposed to military survival training. Biol Psychiatry 47:902-909

Morgan CA III, Southwick S, Hazlett G, Rasmusson A, Hoyt G, Zimolo Z, Charney D (2004) Relationships among plasma dehydroepiandrosterone sulfate and cortisol levels, symptoms of dissociation and objective performance in humans exposed to acute stress. Arch Gen Psychiatry 61:819-825

Morilak DA, Barrera G, Echevarria DJ, Garcia AS, Hernandez A, Ma S, Petre CO (2005) Role of brain norepinephrine in the behavioral response to stress. Prog Neuropsychopharmacol Biol Psychiatry 29:1214-1224

Murphy FC, Nimmo-Smith I, Lawrence AD (2003) Functional neuroanatomy of emotions: a meta-analysis. Cogn Affect Behav Neurosci 3:207-233

Neri DF, Wiegmann D, Stanny RR, Shappell SA, McCardie A, McKay DL (1995) The effects of tyrosine on cognitive performance during extended wakefulness. Aviat Space Environ Med 66:313-319

Nisenbaum LK, Abercrombie ED (1993) Presynaptic alterations associated with enhancement of evoked release and synthesis of norepinephrine in hippocampus of chronically cold-stressed rats. Brain Res 608:280-287

Opstad K (1994) Circadian rhythm of hormones is extinguished during prolonged physical stress, sleep and energy deficiency in young men. Eur J Endocrinol 131:56-66

Owasoyo JO, Neri DF, Lamberth JG (1992) Tyrosine and its potential use as a countermeasure to performance decrement in military sustained operations. Aviat Space Environ Med 63:364-369

Pichon S, de Gelder B, Grezes J (2008) Emotional modulation of visual and motor areas by dynamic body expressions of anger. Soc Neurosci 3:199-212

Rauch TM, Lieberman HR (1990) Tyrosine pretreatment reverses hypothermia-induced behavioral depression. Brain Res Bull 24: $147-150$
Scott JP, McNaughton LR, Polman RC (2006) Effects of sleep deprivation and exercise on cognitive, motor performance and mood. Physiol Behav 87:396-408

Shukitt-Hale B, Banderet LE, Lieberman HR (1998) Elevationdependent symptom, mood, and performance changes produced by exposure to hypobaric hypoxia. Int J Aviat Psychol 8:319-334

Shukitt-Hale B, Stillman MJ, Lieberman HR (1996) Tyrosine administration prevents hypoxia-induced decrements in learning and memory. Physiol Behav 59:867-871

Shurtleff D, Thomas JR, Ahlers ST, Schrot J (1993) Tyrosine ameliorates a cold-induced delayed matching-to-sample performance decrements in rats. Psychopharmacology 112:228-232

Steffian G, Bluestein BW, Ogrisseg J, Doran AP, Morgan CA III (2005) Code of conduct and the psychology of captivity: training, coping and reintegration. In: Adler AB, Castro CA, Britt TW (eds) Military life: the psychology of serving in peace and combat: operational stress, vol 2. Praeger Security International, Westport, CT, pp 83-120

Stone EA (1975) Stress and catecholamines. In: Freidhoff AJ (ed) Catecholamines and behavior. Plenum, New York, pp 31-72

Sudha S, Pradhan N (1995) Stress-induced changes in regional monamine metabolism and behavior in rats. Physiol Behav 57: 1061-1066

Taylor MK, Mujica-Parodi LR, Padilla GA, Markham AE, Potterat EG, Momen N, Sander TC, Larson GE (2009) Behavioral predictors of acute stress symptoms during intense military training. J Trauma Stress 22:212-217

Taylor MK, Sausen KP, Mujica-Parodi LR, Potterat EG, Yanagi MA, Kim H (2007) Neurophysiologic methods to measure stress during survival, evasion, resistance, and escape training. Aviat Space Environ Med 78:B224-B230

Thomas JR, Lockwood PA, Singh A, Deuster PA (1999) Tyrosine improves working memory in a multitasking environment. Pharmacol Biochem Behav 64:495-500

Watson E, Wilk S (1975) Assessment of cerebrospinal fluid levels of dopamine metabolites by gas chromatography. Psychopharmacology 42:57-62

Westerink BHC, De Vries JB (1991) Effect of precursor loading on the synthesis rate and release of dopamine and serotonin in the striatum: a microdialysis study in conscious rats. J Neurochem 56:228-233

Wurtman RJ, Fernstrom JD (1975) Control of brain monoamine synthesis by diet and plasma amino acids. Am J Clin Nutr 28:638-647

Yeghiayan SK, Luo S, Shukitt-Hale B, Lieberman HR (2001) Tyrosine improves behavioral and neurochemical deficits caused by cold exposure. Physiol Behav 72:311-316 